\title{
Comparing larvicidal Effect of Methanol Extract of the Aerial Parts of Henbane (Hyoscyamus niger L.) and Oleander ( Nerium oleander L.) plants on Anopheles spp Larvae (Diptera: Culicidae) in Vitro
}

\author{
Mahmoodreza Behravan, ${ }^{1}$ Mohammad Reza Vaezi-Kakhki, ${ }^{2}$ and Amin Baharshahi, ${ }^{3}$, \\ ${ }^{1}$ Department of Microbiology and Hepatitis Research Center, Faculty of Paramedical, Birjand University of Medical Sciences, Birjand, IR Iran \\ ${ }^{2}$ Department of Biology, Faculty of Basic Science, Hakim Sabzevai University, Sabzevar, IR Iran \\ ${ }^{3}$ Young Researchers and Elite Club, Shirvan Branch, Islamic Azad University, Shirvan, IR Iran \\ "Corresponding author: Amin Baharshahi, Department of Microbiology, Faculty of Paramedical, Birjand University of Medical Science, Ghaffari St., Birjand, IR Iran. Tel: \\ +98-9365401811, E-mail: amin.baharshahi@outlook.com
}

Received 2016 September 01; Revised 2016 November 02; Accepted 2017 October 04.

\begin{abstract}
Background: Malaria is an infectious disease by fever and chills, anemia and splenomegaly genus Plasmodium parasite is the agent it. One of the easiest and least expensive methods to prevent this disease is removing the vector that usually by been done insecticides and chemical pesticides, but nowadays due to the damaging effects of by toxic chemicals is currently trying to organic toxic and plant compounds used to combat the pests. So in this study used from the Hyoscyamus niger L. and Nerium oleander L. to destroy the larvae of this vectors and positive results were compared these two plants together.

Methods: In this experimental study, H. niger and N. oleander collected and dried to extraction by methanol usingthe Rotary Evaporator. Mosquito larvae collected from stagnant water pits and ponds around the Birjand, Iran and order to apply the relevant identity tests and isolation of Anopheles spp mosquito larvae. Survival measurement were used to estimate LC50 values using Probit analysis in Excel 2010 and SPSS (ver 20) software.

Results: Both Hyoscyamus niger and Nerium oleander had positive effects on destroying the Anopheles spp larvae and between obtained results, the most effective extract for destroying the mosquitoes Anopheles spp larvae, was the flower extract of henbane $(\mathrm{LC} 50=0 / 26 \mathrm{ppm})$ and the weakest one, was the leaves extract of oleander $(\mathrm{LC} 50=4 / 85 \mathrm{ppm})$.

Conclusions: According to the results, the flower extract of henbane is recommended as a toxic, organic and natural compounds to fight Anopheles spp mosquito larvae, which it is stronger and more effective compared to the other parts of these two plants.
\end{abstract}

Keywords: Malaria, Anopheles spp Larvae, Hyoscyamus niger L., Nerium oleander L.

\section{Background}

Malaria is clinically a hemolytic feverous disease associated with chills, fever and sweats, anemia, and splenomegaly. Its parasite (Plasmodium spp) lives in the red blood cells, and it is transmitted by bloodthirsty Anopheles spp [1]. As approximately one milliard people of the world's population are at the risk of malaria disease and in 2015, there were an estimated 438,000 malaria deaths (range 236,000 - 635,000) worldwide. Most of these deaths occurred in the African region (90\%), followed by the South-East Asia region (7\%) and the Eastern Mediterranean region (2\%), therefore, malaria can be considered as the most important parasitic disease in the world [2]. Nineteen species of Anopheles spp have been reported in Iran, that seven of them are known as malaria vectors. Anopheles stephensi has been reported as the most important vector in Iran [3].

H. niger (Solanales: Solanaceae) plant known also as henbane is one of the important medicinal plants, and it belongs to Solanaceae family spreading widely in Asia and Europe. The importance of this plant is due to high alkaloid compounds such as hyoscyamine and scopolamine that hyoscyamine sulfate and scopolamine-hydrobromide drugs are produced of them, respectively. Hyoscyamine sulfate and scopolamine-hydrobromide have respectively anticholinergic and anti-spasmodic properties. The plant has also anti-spasmodic, analgesic and sedative properties [4]. Anglo-Saxons named this plant as henbane because hens were paralyzed after eating the seeds of this plant [5].

Oleander (Gentianales: Apocynaceae) is an ornamental plant that has densely branched shrub with cross leaves, native to southern Europe, North Africa and South East Asia [6]. It grows generally in sub-trophic and tropic regions [7]. All parts of this plant are toxic to humans and other creatures $[8,9]$. Toxic substance of this plant can cause nausea, vomiting, abdominal pain, diarrhea, hyperkalemia and the dysrhythmias in humans, and approximately $4 \%-10 \%$ of people poisoned by it die annually [10]. $N$. Oleander plant contains mixture of cardiac glycosides 
such as a group of cardenolides containing oleandrin, folinerin, and digitoxin, impairing the heart's electrical conductivity [11]. This plant has medicinal properties, including antibacterial $[7,12,13]$, anti-inflammatory and analgesic $[14,15]$, cytotoxic [16], and antidiabetic [17] properties. It is also considered as safety system Recovery drug [18] and heart stimulant drug [19]. In addition, it has neuroprotection effects [20].

One way to prevent the spread of malaria is fighting against its vector mosquito known as Anopheles spp. Chemical pesticides and insecticides are used for this purpose. However, these chemical pesticides have devastating and destructive effects on the environment and ecosystems. Additionally, increased use of these toxins has caused carrier resistance against it [21]. Therefore, the aim of this study was to use the extract of aerial parts of oleander and henbane as larvicidal to fight against larvae of Anopheles spp. After performing the related tests, the obtained results were recorded and finally the larvicidal effect of different parts of these plants was compared.

\section{Methods}

Isolation of plant extracts: In this experimental study, aerial parts of henbane (Figure 1) were collected from the foothills of the Tabas village ( $\left.36^{\circ} 24^{\prime} 15.9^{\prime \prime} \mathrm{N}, 57^{\circ} 42^{\prime} 30.5^{\prime \prime} \mathrm{E}\right)$ near the Sabzevar, Iran in May 2015, and the aerial parts of the oleander plant (Figure 2) were collected from Hakim Sabzevari University campus ( $\left.36^{\circ} 17^{\prime} 53.8^{\prime \prime} \mathrm{N}, 57^{\circ} 40^{\prime} 47.9^{\prime \prime} \mathrm{E}\right)$ at the same time (Figure 3). After rinsing with water, they were kept at room temperature for 15 days, away from direct sunlight so that they can be dried completely. One sample of each of two plants was sent to herbarium of Mashhad Ferdowsi University to identify and determine the species, and species codes were received for each plant that they were 32,493 for henbane and 10109 for $N$. oleander. A modified method was applied for the plants extraction [22]; after drying, different parts of these plants, including stems, leaves and flowers were separated and milled. Then, 100 grams' powder of each part of plant was mixed with $500 \mathrm{~mL}$ of methanol solvent. After that, they were kept at $20-25^{\circ} \mathrm{C}$ for 72 hours in a dark place away from sunlight. In the next step, the obtained extracts were passed from filter what man paper No. 2 separately. Finally, concentrated tarlike extract was obtained using Rotary evaporator to dry and eliminate the solvent.

Collecting Anopheles larvae: According to WHO recommendation [23], 4th instar larvae of Anopheles spp in August 2015, researcher referred to ponds and pits of stagnant water around Birjand, Iran (with geographical position $32^{\circ} 49^{\prime} 42.8^{\prime \prime} \mathrm{N}, 59^{\circ} 10^{\prime} 38.6^{\prime \prime} \mathrm{E}$ ) (Figure 3). Anopheles spp larvae were hunted and collected using ladling method.

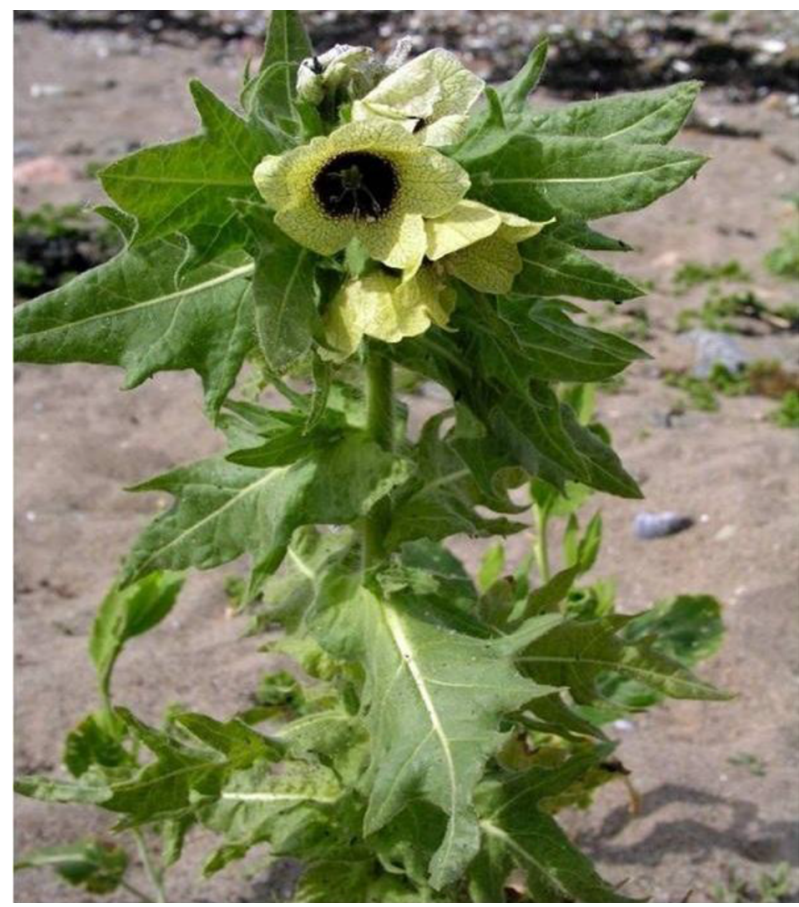

Figure 1. Habitus of $H$. niger Plant

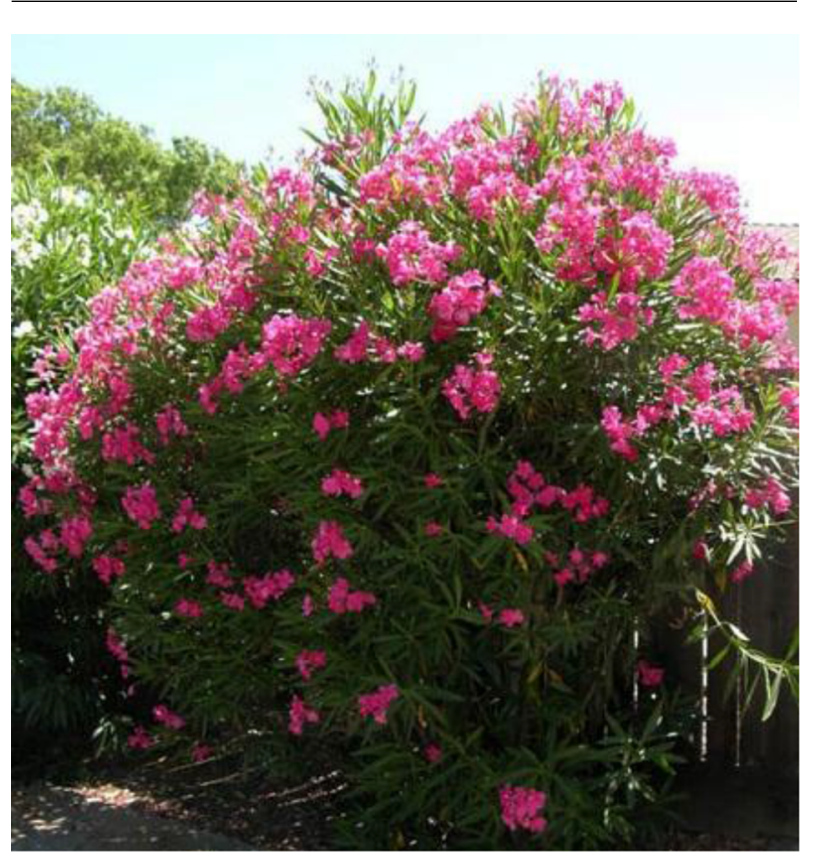

Figure 2. Habitus of N. oleander Plant

Then, larvae were transferred to parasitology laboratory of Birjand University of Medical Sciences, and the third and 


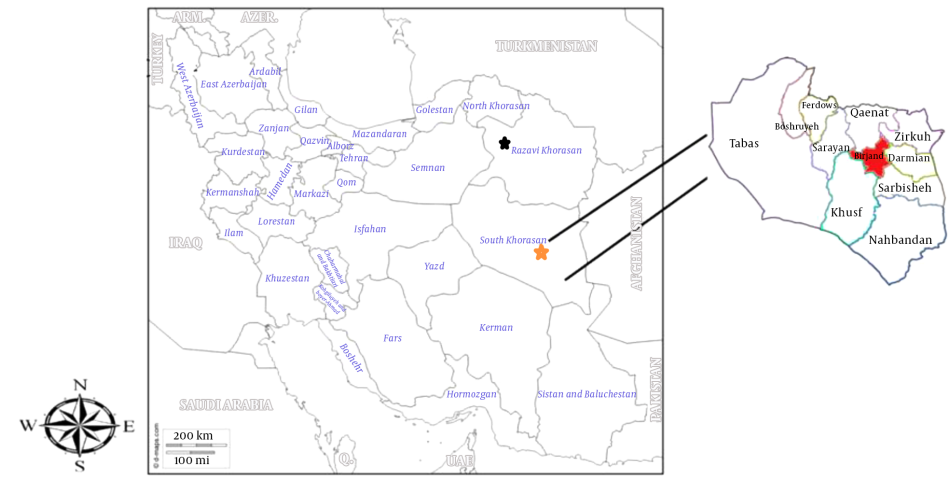

Yellow star: Birjand-location collected the Anopheles spp larvae.

fourth instar larvae of Anopheles spp were identified and separated by the relevant expert.

Larvicidal bioassay: concentrations of $0.25,0.5,1,2,4$ $\mathrm{mg} / \mathrm{mL}$ were prepared from stem, leaf and flower extracts of oleander and henbane by distilled water solvent, according to the recommendation of the world health organization [24]. One concentration of the extract related to one part of oleander and henbane was poured to each plate. Then,10 Anopheles spp larvae were placed inside each plate and 10 larvae, as control, were placed in a plate containing distilled water. Plates were transferred to refrigerator with temperature of $+4^{\circ} \mathrm{C}$ away from the light (in order to avoid metamorphosis). Then, at 6, 12, 24, 48 and 72 hours, it was examined that if they are alive or dead by hitting the needle tip to them and observing their reaction to stimuli, and results were recorded [25]. This test was conducted twice and mean number of killed larvae was calculated for each part and concentration. Then, data analysis was performed using probit analysis in Excel 2010 and SPSS (ver. 20) software.

\section{Results}

This study was an experiment conducted on the larvae of Anopheles spp in Birjand, Iran. Findings of the study showed that methanol extract of henbane leaves had no significant impact on larvae of Anopheles spp at the first 24 hours. After 48 hours, the mortality increased so the $P$ value (mean difference between two compared groups) was reduced, so that, after 72 hours, the number of dead larvae increased to the extent that the P value was 0.01, indicating the positive impact of larvicidal of the extract and its LC50 (lethal concentrations in which $50 \%$ of the larvae are killed) was obtained $0.74 \mathrm{ppm}$. However, methanol extract of $N$. oleander leaves had significant larvicidal effect with the passage of time. After 12 hours, it was not significant, while it was significant after 24 and 48 hours when the P value was 0.04 and its LC50 were obtained $7.3 \mathrm{ppm}$ and 4.85 ppm respectively. However, results were not significant after 72 hours by increasing the concentration (Table 1$)$.

In the case of henbane stem extract as time passed, the larvicidal effect became more visible. By increasing the stem extract concentration in the first 24 hours, the p-value was 0.06 , which was much close to significance, while after 72 hours it reached to 0.02 and the LC50 was obtained 0.9 ppm. Oleander stem extract did not show a significant larvicidal effect even with the passage of time (Table 2).

The results obtained for the methanol extract of henbane flower at the first 24 hours indicated that increasing the concentration had no significant impact on larvae of Anopheles spp, while the P value was significant (0.02) after 48 hours, indicating the positive larvicidal effect of the extract. At the same time, the LC50 was 0.26 ppm. However, methanol extract of oleander flower showed a hopeful result with a significant larvicidal effect ( $P$ value of less than 0.05 ) by increasing the concentration at 6,12 and 24 hours. Their LC50 was equal at all three times and its value was obtained $5.06 \mathrm{ppm}$. However, after 48 hours, it was $\mathrm{P}=0.06$ and it was completely non-significant at 72 hours (Table 3 ).

Our findings showed that by increasing time, larger number of larvae died and leaf extract of henbane leaf at all times $(6,12,24,48$ and 72 hours) showed more larvicidal effect on Anopheles spp compared to methanol extract of oleander leaf (Figure 4). In the case of stem, only methanol extract of henbane stem had significant impact on destroying the larvae after 72 hours, while stem extract of oleander had no significant impact on larvae (Figure 5). With regard to flower extract, methanol extract of henbane flower 
Table 1. Lethal Concentration Values for Various Leaf Extracts of H. niger and N. oleander Against Third and Fourth Stage Larval Mosquitoes of Anopheles spp. (Mortality Was not Observed in Control)

\begin{tabular}{|c|c|c|c|c|c|c|}
\hline \multirow[t]{2}{*}{ Extracts } & & \multicolumn{5}{|c|}{ Period of Exposure, $h$} \\
\hline & & 6 & 12 & 24 & 48 & 72 \\
\hline \multirow{2}{*}{ H. niger leaf } & LC50 & - & 43.35 & 10.84 & 2.47 & 0.74 \\
\hline & PValue & - & 0.42 & 0.28 & 0.04 & 0.04 \\
\hline \multirow{2}{*}{ N. oleander leaf } & LC50 & - & 14.82 & 7.30 & 4.85 & 2.83 \\
\hline & PValue & - & 0.06 & 0.04 & 0.04 & 0.18 \\
\hline
\end{tabular}

Table 2. Lethal Concentration Values for Various Stem Extracts of H. niger and N. oleander Against Third and Fourth Stage Larval Mosquitoes of Anopheles spp. (Mortality Was not Observed in Control)

\begin{tabular}{|c|c|c|c|c|c|c|}
\hline \multirow[t]{2}{*}{ Extracts } & & \multicolumn{5}{|c|}{ Period of Exposure, $h$} \\
\hline & & 6 & 12 & 24 & 48 & 72 \\
\hline \multirow{2}{*}{ H. niger stem } & LC50 & 0.11 & 0.11 & 0.11 & 17.79 & 0.90 \\
\hline & PValue & 0.6 & 0.6 & 0.6 & 0.31 & 0.02 \\
\hline \multirow{2}{*}{ N. oleander stem } & LC50 & 3.32 & 5.97 & 1.64 & 1.64 & 0.46 \\
\hline & PValue & 0.36 & 0.32 & 0.13 & 0.14 & 0.13 \\
\hline
\end{tabular}

Table 3. Lethal Concentration Values for Various Flower Extracts of H. niger and N. oleander against third and fourth stage larval mosquitoes of Anopheles spp. (Mortality was not observed in control)

\begin{tabular}{|c|c|c|c|c|c|c|}
\hline \multirow[t]{2}{*}{ Extracts } & & \multicolumn{5}{|c|}{ Period of Exposure, $h$} \\
\hline & & 6 & 12 & 24 & 48 & 72 \\
\hline \multirow{2}{*}{ H. niger flower } & LC50 & 2.57 & 1.74 & 0.54 & 0.26 & 0.07 \\
\hline & PValue & 0.18 & 0.12 & 0.13 & 0.02 & 0.06 \\
\hline \multirow{2}{*}{ N. oleander flower } & LC50 & 5.06 & 5.06 & 5.06 & 1.63 & 0.85 \\
\hline & PValue & 0.02 & 0.02 & 0.02 & 0.06 & 0.10 \\
\hline
\end{tabular}

showed higher larvicidal power compared to methanol extract of oleander flower (Figure 6) (Mortality was not observed in control).

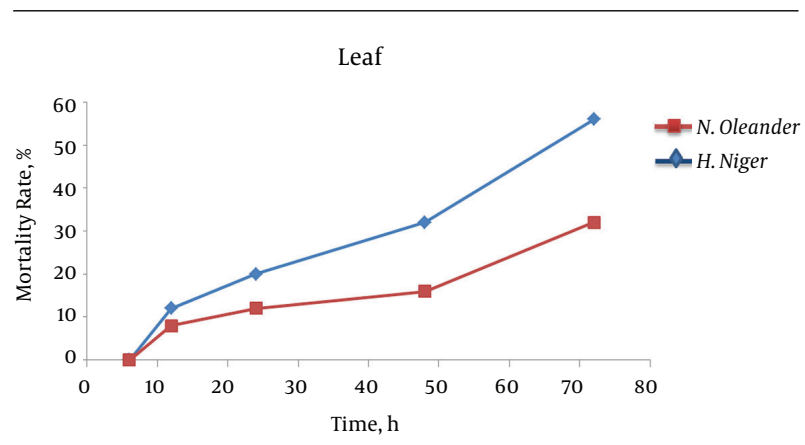

Figure 4. Larvicidal Effects of Leaf Extract of Nerium oleander and Hyoscyamus niger During 72 Hours

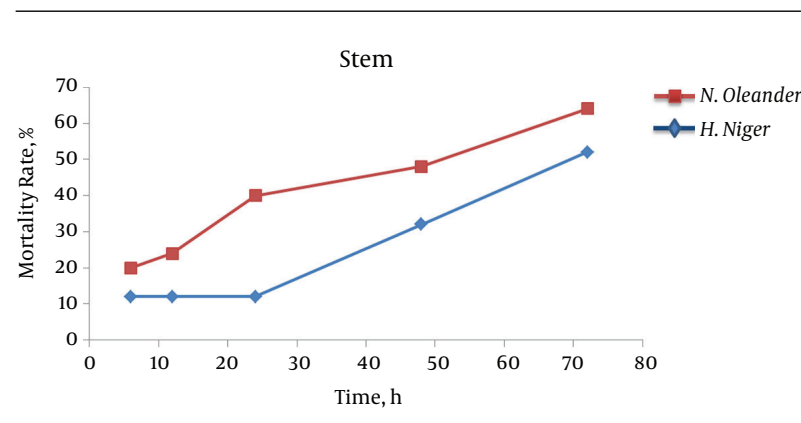

Figure 5. Larvicidal Effects of Stem Extract of Nerium oleander and Hyoscyamus niger During 72 Hours

\section{Discussion}

Arthropods are important factors in transmission of various pathogens in Iran and this issue has become a ma- 


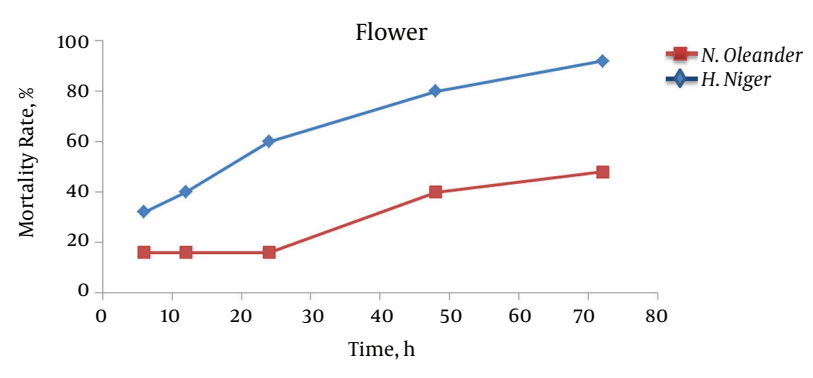

Figure 6. Larvicidal Effects of Flower Extract of Nerium oleander and Hyoscyamus niger During

jor health challenge in the country $[26,27]$. One of the main methods to prevent parasitic diseases such as malaria is to fight against vectors of that disease. The mosquito vector of malaria is Anopheles spp. Chemical pesticides have always been used to fight against these vectors, while these compounds have adverse effect on environment and ecosystem. In addition, excessive use of these pesticides leads to resistance of vector against it. Therefore, scientists have attempted to find safe alternatives for environment and human health and other non-target creatures. The important alternatives in this regard are various methods for biological controlling and using organic pesticides produced by plants.

These organic pesticides destroy insects even at lower concentrations, while they are not hazardous for larger animals. Additionally, these extracts obtained from plants such as chemical pesticides often have no accumulation property, causing no threat for ecosystem and consumer animals in the long term. In this study, it was found that extract of aerial parts of henbane have more impact on destruction of Anopheles spp larvae compared to oleander plants. In this regard, the strongest extract to destroy the Anopheles spp larvae at 48 hours belonged to henbane extract with $\mathrm{LC} 50=0.26 \mathrm{ppm}$, while the weakest extract was oleander leaf extract with $\mathrm{LC} 50=4.85 \mathrm{ppm}$. While reports on anti-larval activities in the case of aromatic plants properties are increasing in various countries, no study has been reported on larvicidal impact of henbane. Additionally, one study was conducted on larvicidal effect of oleander plant by Fakourziba et al. (2015) at Shiraz University of Medical Sciences. In the mentioned study, the effect of five different extracts of oleander flowers and leaves prepared by five solvents of acetone, petroleum, benzene, chloroform, and water against larvae of Anopheles stephensi was investigated.

Results showed that benzene extract of the flowers of this plant had the largest larvicidal power and chloroformic extract of this plant leaf had the lowest larvicidal effect [21]. These results are consistent with results of our study, so that LC50 of oleander leaf extract at 24 and 48 hours was respectively $4.85 \mathrm{ppm}$ and $3.73 \mathrm{ppm}$, while this value for flower extract at 24 and 48 hours was respectively $1.63 \mathrm{ppm}$ and $5.06 \mathrm{ppm}$. This shows that methanol extract of oleander flower has higher impact than its leaf extract. In another study conducted by Bagari et al. (2013) in Morocco, toxic effects of oleander leaf on desert locust larvae were examined. Results showed that oleander leaf has positive impact on controlling desert locust larvae [9]. In another study conducted by Lokesh et al. (2010) in India, larvicidal leaf activity of $N$. oleander and Trigonella foenum L. against mosquito larvae was studied. They concluded that the leaf extracts of both plants have higher larvicidal effect, while mixture of them had stronger larvicidal activity [28].

In some studies, to test the impact of extracts on mosquito's larvae, a species of mosquito is reproduced and reproduced larvae of same species is used to test the impact of different extracts on mosquito's larvae, which it reflects only the impact of the extract on same species. However, as the goal of this study was not just destroying the larva of a species of Anopheles spp and the result was introducing an organic and natural compound to fight against larva of all Anopheles spp in Birjand, Iran.

As oleander and henbane plants are native for Iran, these plant extracts can be used as native tool to fight against Anopheles spp. This insecticide is biodegradable and this is its advantage over other its chemical products. It seems that these plants can be useful in destroying the Anopheles spp larvae, thanks to Alkaloid compounds such as oleandrin, folinerin, and digitoxin in oleander, hyoscyamine, and scopolamine in henbane. The findings of this study can be used as an effective solution to fight against larvae of Anopheles spp that are vectors of malaria in developing countries and countries where malaria is endemic, without imposing environmental damage.

\section{Acknowledgments}

The study was financially supported by the office of vice-chancellor for research of Birjand University of Medical Sciences (grant No: 1109).

\section{Footnotes}

Authors' Contribution: All authors had equal role in design, work, statistical analysis and manuscript writing.

Conflict of Interest: The authors declare no conflict of interest.

Funding/Support: Birjand University of Medical Sciences. 


\section{References}

1. Knell AJ. Malaria. Oxford: Oxford University Press; 1991.

2. Benelli G, Mehlhorn $\mathrm{H}$. Declining malaria, rising of dengue and Zika virus: insights for mosquito vector control. Parasitol Res. 2016;115(5):1747-54. doi: 10.1007/s00436-016-4971-z. [PubMed: 26932263].

3. Bagheri M. Phytochemical and biological investigation of essential oil. Tehran: Faculty of Pharmacy Tehran University of Medical Sciences; 1999 . pp. 15-34.

4. Alaghemand A, Ghorbanpour M, Asli DE, Moghaddasian B. Calcium fertilization effects on hyoscyamine and scopolamine accumulation in henbane (Hyoscyamus niger L.) under hydroponic culture. Eur JExp Biol. 2013;3(3):228-32.

5. Dulger B, Hacioglu N, Goncu BS, Gucin F. Antifungal activity of seeds of Hyoscyamus niger L.(Henbane) against some clinically relevant fungal pathogens. Asian J Chemi. 2010;22(8):6321-4.

6. Fu L, Zhang S, Li N, Wang J, Zhao M, Sakai J, et al. Three new triterpenes from Nerium oleander and biological activity of the isolated compounds. J Nat Prod. 2005;68(2):198-206. doi: 10.1021/np040072u. [PubMed: 15730243].

7. Derwich E, Benziane Z, Boukir A. Antibacterial activity and chemical composition of the essential oil from flowers of Nerium oleander. Electron J Environ Agric Food Chem. 2010;9(6):1074-84.

8. Nazemi RJ, Moharamipour S. Repellency of Nerium oleander L., Lavandulla officinalis L. and Ferula assafoetida L. extracts on Tribolium castaneum (Herbst). Iran J Med Aromat Plants. 2008:443-52.

9. Bagari M, Bouhaimi A, Ghaout S, Chihrane J. The toxic effects of Nerium oleander on larvae of the desert locust Schistocerca gregaria (Forskål, 1775)(Ortoptera, Acrididae). Zool Baetica. 2013;24:193-203.

10. Szabuniewicz M, Schwartz WL, McCrady JD, Russell LH, Camp BJ. Experimental oleander poisoning and treatment. Southwestern Veterinarian; 1972.

11. Langford SD, Boor PJ. Oleander toxicity: an examination of human and animal toxic exposures. Toxicology. 1996;109(1):1-13. [PubMed: 8619248].

12. Roni M, Murugan K, Panneerselvam C, Subramaniam J, Hwang JS. Evaluation of leaf aqueous extract and synthesized silver nanoparticles using Nerium oleander against Anopheles stephensi (Diptera: Culicidae). Parasitol Res. 2013;112(3):981-90. doi: 10.1007/s00436-012-3220-3. [PubMed: 23239092].

13. Huq MM, Jabbar A, Rashid MA, Hasan CM, Ito C, Furukawa H. Steroids from the roots of Nerium oleander. J Nat Prod. 1999;62(7):1065-7. doi 10.1021/np990031b. [PubMed: 10425146].

14. Suganya RS, Priya K, Roxy BM. Phytochemical screening and antibacterial activity from Nerium oleander and evaluate their plant mediated nanoparticle synthesis. Int Res J Pharm. 2012;3:285-8.
15. Erdemoglu N, Kupeli E, Yesilada E. Anti-inflammatory and antinociceptive activity assessment of plants used as remedy in Turkish folk medicine. J Ethnopharmacol. 2003;89(1):123-9. [PubMed:14522443].

16. Kumar S, Anand GR. Evaluation of anti-inflammatory activity of Nerium oleander. Pharmacia. 2010;1:33-6.

17. El Sawi NM, Geweely NS, Qusti S, Mohamed M, Kamel A. Cytotoxicity and Antimicrobial Activity ofNerium oleanderExtracts. J Appl Animal Res. 2010;37(1):25-31. doi:10.1080/09712119.2010.9707089.

18. Mwafy SN, Yassin MM. Antidiabetic activity evaluation of glimepiride and Nerium oleander extract on insulin, glucose levels and some liver enzymes activities in experimental diabetic rat model. Pak J Biol Sci. 2011;14(21):984-90. [PubMed: 22514888]

19. Al-Farwachi MI. In vivo and in vitro Immunmodulatory Activities of Nerium oleander Aqueous Leaf Extract in Rabbits. J Anim Vet Adv. 2007;14:1047-50.

20. Adome RO, Gachihi JW, Onegi B, Tamale J, Apio SO. The cardiotonic ef fect of the crude ethanolic extract of Nerium oleander in the isolated guinea pig hearts. Afr Health Sci. 2003;3(2):77-82.

21. Fakoorziba MR, Moemenbellah-Fard MD, Azizi K, Mokhtari F. Mosquitocidal efficacy of medicinal plant, Nerium oleander (Apocynaceae), leaf and flower extracts against malaria vector, Anopheles stephensi Liston (Diptera: Culicidae) larvae. Asian Pac J Trop Dis. 2015;5(1):33-7.

22. Addae-Kyereme J, Croft SL, Kendrick H, Wright CW. Antiplasmodial activities of some Ghanaian plants traditionally used for fever/malaria treatment and of some alkaloids isolated from Pleiocarpa mutica; in vivo antimalarial activity of pleiocarpine. J Ethnopharmacol. 2001;76(1):99-103. doi: 10.1016/s0378-8741(01)00212-4.

23. World Health Organization. Instructions for determining the susceptibility or resistance of mosquito larvae to insecticides. Geneva: WHO 1981.

24. World Health Organization . Insecticide resistance and vector control, 17th report of WHO expert committee on insecticide. Technical Report Series; 1970.

25. Raveen R, Kamakshi KT, Deepa M, Arivoli S, Tennyson S. Larvicidal activity of Nerium oleander L.(Apocynaceae) flower extracts against Culex quinquefasciatus Say (Diptera: Culicidae). Int J Mosquito Res. 2014;1(1):36-40.

26. Finney DJ. Probit analysis. Combrige: Combrige University Press; 2012.

27. Fakoorziba MR, Baseri A, Eghbal F, Rezaee S, Azizi K, MoemenbellahFard MD. Post-earthquake outbreak of cutaneous leishmaniasis in a rural region of southern Iran. Ann Trop Med Parasitol. 2011;105(3):21724. doi: 10.1179/136485911X12899838683449. [PubMed: 21801500].

28. Lokesh R, Leonard Barnabas E, Madhuri P, Saurav K, Sundar K. Larvicidal activity of Trigonella foenum and Nerium oleander leaves against mosquito larvae found in Vellore city, India. Curr Res J Biol Sci. 2010;2(3):154-60. 